\title{
Analysis of human equilibrative nucleoside transporter 1 (hENT1) protein in non-Hodgkin's lymphoma by immunohistochemistry
}

\author{
Laura Chow ${ }^{1}$, Raymond Lai ${ }^{2}$, Laith Dabbagh ${ }^{2}$, Andrew Belch ${ }^{1,3}$, James D Young ${ }^{4}$, \\ Carol E Cass ${ }^{5,6}$ and John R Mackey ${ }^{1,3}$ \\ ${ }^{1}$ Department of Medical Oncology, Cross Cancer Institute, Edmonton, Alberta, Canada; ${ }^{2}$ Department of \\ Laboratory Medicine \& Pathology, Cross Cancer Institute, Edmonton, Alberta, Canada; ${ }^{3}$ Department of \\ Experimental Oncology, Cross Cancer Institute, Edmonton, Alberta, Canada; ${ }^{4}$ Department of Physiology, \\ University of Alberta, Edmonton, Alberta, Canada; ${ }^{5}$ Department of Biochemistry, University of Alberta, \\ Edmonton, Alberta, Canada and ${ }^{6}$ Department of Oncology, University of Alberta, Edmonton, Alberta, Canada
}

\begin{abstract}
The human equilibrative nucleoside transporter 1 (hENT1) is a member of the equilibrative nucleoside transporter family that mediates cellular entry of gemcitabine, cytarabine, and fludarabine. Deficiency in hENT1 confers resistance to toxicity of these drugs in a variety of model systems. Since some nucleoside analogs have a role in treating patients with non-Hodgkin's lymphoma (NHL), this study was undertaken to assess hENT1 abundance in NHL. A total of 115 cases of NHL of various subtypes and 15 reactive lymph nodes were evaluated for the presence of hENT1 protein using immunohistochemistry applied to frozen tissues. Samples were considered positive when $\geq \mathbf{5 0} \%$ of neoplastic cells showed immunostaining. In reactive lymph nodes, hENT1 was confined to the germinal centers, whereas mantle zone B-cells and interfollicular T-cells were negative. In NHL, a relatively high frequency of hENT1 positivity was found in Burkitt lymphoma/leukemia (63\%), diffuse large B-cell lymphoma (DLCL; 45\%), and follicular lymphoma (40\%). In DLCL, $26 \%$ of cases were positive for CD10, and CD10-positive DLCL cases were more likely to be hENT1 positive than CD10-negative cases $(P=0.025)$. A lower frequency of hENT1 positivity was found in mantle cell lymphoma $(13 \%)$ and peripheral Tcell lymphomas (37\%). All marginal zone lymphomas $(n=5)$, chronic lymphocytic leukemia small lymphocytic lymphomas $(n=10)$, plasmacytoma $(n=3)$, acute lymphoblastic lymphoma/leukemia, and anaplastic large-cell lymphomas $(n=5)$ were negative. In conclusion, hENT1 was most frequently found in benign and malignant follicular center cells. Prospective studies to assess the value of hENT1 immunostaining in predicting resistance to nucleoside chemotherapy for NHL are warranted.
\end{abstract}

Modern Pathology (2005) 18, 558-564, advance online publication, 29 October 2004; doi:10.1038/modpathol.3800323

Keywords: non-Hodgkin's lymphoma; hENT1; nucleoside transport immunohistochemistry

Nucleoside analog chemotherapy is increasingly important in the therapy of many hematological malignancies. Fludarabine (9- $\beta$-D-arabinosyl-2-fluoroadenine) is an effective frontline therapy for small lymphocytic lymphoma. ${ }^{1}$ Gemcitabine $\left(2^{\prime}, 2^{\prime}\right.$-difluorodeoxycytidine) benefits some patients with nonHodgkin's lymphoma (NHL) unresponsive to the frontline chemotherapy, ${ }^{2-8}$ and cytarabine (1- $\beta$-D-

Correspondence: Dr JR Mackey, MD, FRCPC, Cross Cancer Institute, 11560 University Avenue, Edmonton, AB, Canada T6G 1Z2.

E-mail: johnmack@cancerboard.ab.ca

Received 1 March 2004; revised 13 September 2004; accepted 15 September 2004; published online 29 October 2004 arabinofuranosyl cytosine) is a standard salvage agent in relapsed aggressive lymphomas. ${ }^{9}$

Nucleoside analogs are relatively hydrophobic, and do not readily cross plasma membranes by diffusion. ${ }^{10,11}$ To reach their intracellular targets, most anticancer nucleosides require the presence of specialized nucleoside transport (NT) proteins in plasma membranes. ${ }^{10,12}$ The recent isolation and functional expression of cDNAs encoding human (h) NT proteins ${ }^{13-18}$ has identified five members of two structurally unrelated protein families that are designated ENT and CNT, depending on whether they mediate, respectively, equilibrative (E) or concentrative (C) NT processes. The hENT proteins have approximately 450 amino-acid residues ${ }^{13-16}$ and 11 predicted transmembrane domains, whereas 
the hCNT proteins have approximately 650 aminoacid residues and 13 predicted transmembrane domains. ${ }^{10,11,17,19}$ Most human cells possess plasma membrane hENT1, as shown by (i) inhibition of cellular nucleoside uptake on exposure to nanomolar levels of nitrobenzylmercaptopurine ribonucleoside (NBMPR), a specific and tight-binding inhibitor of hENT1 and (ii) quantitation of high-affinity NBMPRbinding sites. Since hENT1 abundance is highly variable in human tissues, and hENT1-deficient cells demonstrate resistance to several anticancer nucleosides, ${ }^{12}$ hENT1 abundance may be a determinant of response to nucleoside drugs in some cancers.

We recently developed an immunohistochemical assay for the detection of hENT1 in frozen human tissues using high-affinity, high-specificity monoclonal anti-hENT1 antibodies. ${ }^{20}$ Since nucleoside analogs have an important role in treating patients with NHL, we have evaluated hENT1 immunostaining in benign lymph nodes as well as NHL of various subtypes.

\section{Materials and methods}

\section{Patient Samples}

Frozen tissues from 115 patients with de novo NHL and 15 benign reactive lymph nodes, collected between 1996 and 2003, were selected for this study. None of these patients received prebiopsy chemotherapy or radiotherapy. Specimens submitted to the Department of Laboratory Medicine and Pathology, Cross Cancer Institute, were snapped frozen in a dry-ice methanol bath, embedded in Optimal Cutting Temperature (Sakura USA, Torrance, CA, USA) and stored at $-80^{\circ} \mathrm{C}$. Diagnoses were made based on morphology and immunophenotyping, as described in the WHO classification schemes for hematologic malignancies. ${ }^{21}$ All procedures were performed with approval of the local institutional research and ethics board.

\section{Production of Monoclonal Antibodies Reactive with hENT1}

Monoclonal antibodies specific for the hENT1 protein were produced by (i) immunization of mice with a synthetic hENT1 peptide (residue 254-273) conjugated to keyhole limpet hemocyanin (KLH) obtained from the Alberta Peptide Institute (Edmonton, Alberta, Canada), and (ii) generation of antibodyproducing hybridomas by standard protocols. The methods used to produce and validate these monoclonal antibodies were previously reported. ${ }^{20,22}$

\section{Immunohistochemistry}

Cryostat sections of lymph node tissues of $4 \mu \mathrm{m}$ thickness were air-dried overnight at room temperature, followed by fixation in acetone for $10 \mathrm{~min}$. Tissue sections were then incubated with antihENT1 antibodies at a concentration of $10 \mu \mathrm{g} / \mathrm{ml}$ in a humidity chamber for $30 \mathrm{~min}$. After three washes with phosphate-buffered saline (PBS), $\mathrm{pH}=7.5$, goat anti-mouse antibodies and horseradish peroxidaselabeled dextran polymer (DAKO ${ }^{\circledR}$ EnVision + , Dako, Carpinteria, CA, USA) were added to the tissue sections and incubated for $30 \mathrm{~min}$ at room temperature. After three washes with PBS, brown color was developed using diaminobenzidene as the chromogen, followed by counterstaining with hematoxylin, and dehydration through graded alcohols and xylene. All incubations were performed at room temperature. Omitting the primary antibodies provided negative controls. hENT1 immunostaining was considered positive when $\geq 50 \%$ (an arbitrary cutoff) of the neoplastic cells showed definitive plasma membrane immunostaining, regardless of the staining intensities. CD10 immunostaining was performed using anti-CD10 antibodies (BD Biosciences, Mississauga, Ontario, Canada) with identical methods as for hENT1, with positive cases defined as $>10 \%$ of neoplastic cells showing definitive immunostaining.

For double immunostaining for hENT1 and CD3, acetone-fixed frozen tissue sections were incubated with anti-CD3 (BD Bioscience, Mississauga, Ontario, Canada) for $30 \mathrm{~min}$ at room temperature, followed by incubation of an IgG anti-mouse secondary antibody. After three washes with PBS, brown color was developed using diaminobenzidene as the chromogen. After washings in running water for $5 \mathrm{~min}$, the tissue sections were washed with PBS and incubated with anti-hENT1 antibody for $30 \mathrm{~min}$ at room temperature. After three washes with PBS, the tissue sections were incubated with a MACH 2 secondaryALP-HRP antibody (Biocare Medical, Walnut Creek, CA, USA) for $30 \mathrm{~min}$, followed by an incubation with Vulcan Fast Red (Biocare Medical) for $30 \mathrm{~min}$ to develop a pink color in positive cells. The slides were then counterstained with hematoxylin.

\section{Results}

\section{hENT1 in Benign Lymph Nodes}

In all of the reactive lymph nodes examined $(n=15)$, hENT1 immunostaining was restricted to the germinal centers (Figure 1). Both centroblasts and centrocytes were positive and staining was mostly membranous, although some degree of cytoplasmic granularity also was present. In all cases, hENT1 immunostaining of endothelial cells was detectable, thereby providing an internal positive control. ${ }^{20,23}$ Double immunostaining confirmed that centroblasts in the germinal centers expressed hENT1 (Figure 1, inset).

\section{hENT1 in NHL}

hENT1 immunostaining was heterogeneous among different types of NHL; the results are summarized in Table 1 and representative images are shown 


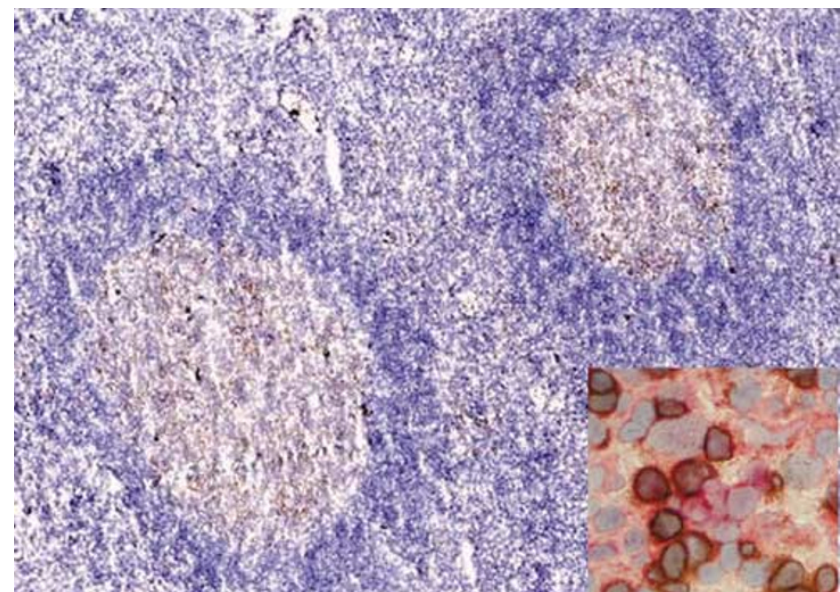

Figure 1 hENT1 staining in reactive lymph nodes was confined to the germinal centers; both mantle zones and interfollicular areas were negative (immunoperoxidase, $\times 20$ ). The inset shows double staining of hENT1 (pink) and CD3 (red) of a benign germinal center; CD3-negative centroblasts were hENT1 positive (immunoperoxidase, $\times 100$ ).

Table 1 Immunohistochemical assessment of hENT1 in benign lymphoid tissues and various types of NHL

\begin{tabular}{lcc} 
Lymphoma subtypes & $\begin{array}{c}\text { Number of } \\
\text { cases }\end{array}$ & $\begin{array}{c}\text { hENT1 } \\
\text { positive }\end{array}$ \\
\hline Burkitt lymphoma/leukemia & 8 & $5(63 \%)$ \\
Diffuse large B-cell lymphoma & 44 & $20(45 \%)$ \\
Follicular lymphoma & 15 & $6^{\mathrm{a}}(40 \%)$ \\
Mantle cell lymphoma & 15 & $2(13 \%)$ \\
Small lymphocytic lymphoma/Chronic & 10 & 0 \\
lymphocytic leukemia & & \\
Marginal zone B-cell lymphoma & 5 & 0 \\
Plasmacytoma & 3 & 0 \\
Acute lymphoblastic lymphoma/leukemia & 2 & 0 \\
Peripheral T-cell lymphoma & 8 & $3(37 \%)$ \\
Anaplastic large cell lymphoma (4 ALK+; & 5 & 0
\end{tabular}

1 ALK-)

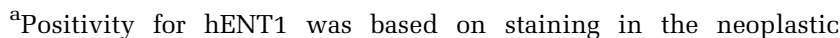
germinal centers only; hENT1 staining in the diffuse areas is described separately in the Results.

in Figure 2. Burkitt lymphoma/leukemia, diffuse large B-cell lymphoma and follicular lymphoma were the subtypes with the highest frequencies of hENT1 immunostaining (63, 45 and $40 \%$, respectively). Lower frequencies of hENT1 immunostaining were found in mantle cell lymphoma (two of 15, $13 \%$ ) and peripheral T-cell lymphoma (three of eight, 37\%). All cases of marginal zone B-cell lymphoma $(n=5)$, chronic lymphocytic leukemia/ small lymphocytic lymphoma $(n=10)$, acute lymphoblastic leukemia/lymphoma $(n=2)$, plasmacytoma $(n=3)$, and anaplastic large-cell lymphoma $(n=5)$ were negative. In the majority of negative cases, $<10 \%$ of neoplastic cells exhibited hENT1 immunostaining.

Since hENT1 expression was confined to germinal center cells in reactive lymph nodes, we tested the

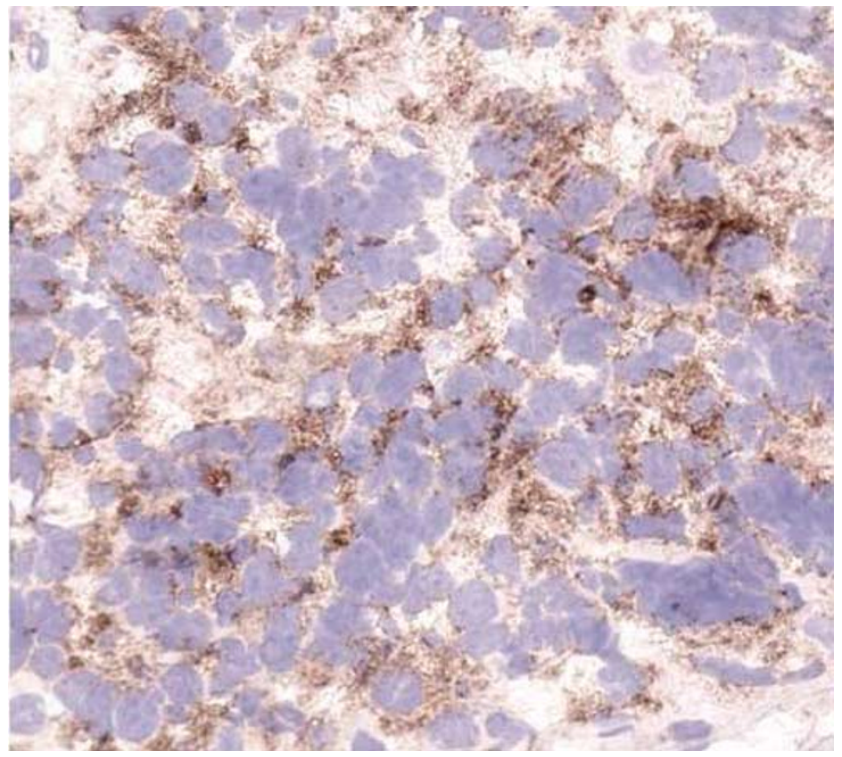

Figure 2 hENT1 staining in a case of CD10-positive diffuse large cell lymphoma (immunoperoxidase, $\times 40$ ).

Table 2 Association between CD10 immunoreactivity and hENT1

\begin{tabular}{lccc}
\hline & $\begin{array}{c}\text { hENT1 } \\
\text { positive }\end{array}$ & $\begin{array}{c}\text { hENT1 } \\
\text { negative }\end{array}$ & $\begin{array}{c}\text { Total number } \\
\text { of cases }\end{array}$ \\
\hline CD10 positive & 9 & 2 & 11 \\
CD10 negative & 13 & 18 & 31 \\
Total cases & 22 & 20 & 42 \\
\hline
\end{tabular}

There was a statistically significant positive association between these two markers ( $P=0.025$, Fisher's exact test).

hypothesis that diffuse large B-cell lymphomas that are derived from follicular center cells would be more commonly positive for hENT1 than those that were not derived from follicular center cells. Expression of CD10, a surrogate marker for follicular center cell origin, was assessed in 42 of 44 cases of diffuse large B-cell lymphoma included in this study that contained sufficient amount of tissues. CD10-positive diffuse large B-cell lymphomas were more likely to be hENT1 positive than CD10negative cases $(P=0.025$, Fisher exact test; Table 2$)$.

Of three cases of follicular lymphoma in which a prominent diffuse component was observed, two cases were hENT1-positive in the low-grade component but the negative in the diffuse largecell component (illustrated in Figure 3). Further evaluation showed that one of these three cases was positive for CD10, in which both the follicular component and the diffuse large-cell component were CD10 positive.

\section{Discussion}

Nucleoside transporter-deficient cells exhibit resistance to cytotoxic nucleosides in vitro. ${ }^{24-28}$ The 


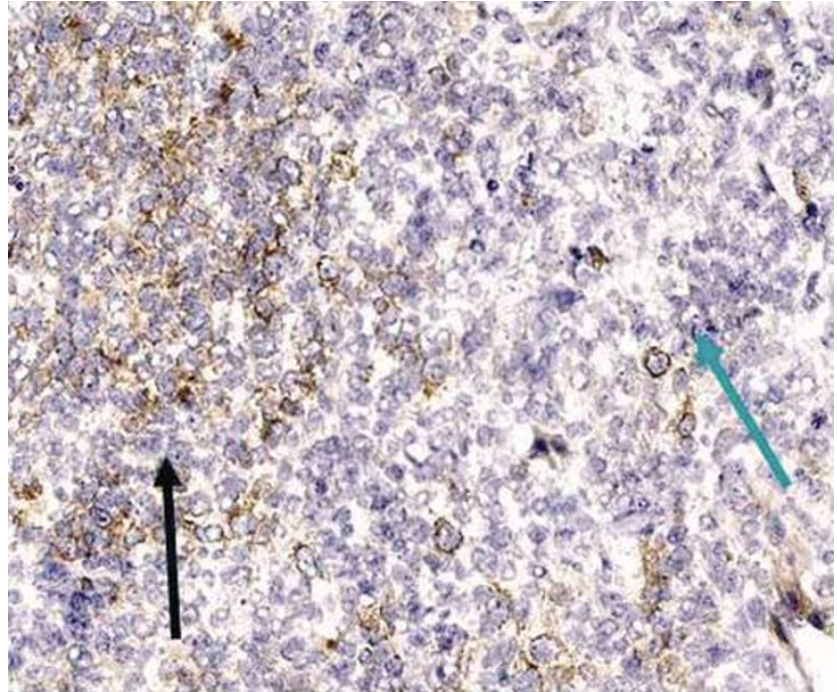

Figure 3 hENT1 staining in one of three follicular lymphomas with a prominent diffuse component, with the neoplastic follicles being positive for hENT1 (left, black arrow) and the diffuse component being negative for hENT1 (right, gray arrow; immunoperoxidase, $\times 20$ )

plasma membrane abundance of hENT1 protein is a major determinant of the efficiency of cellular accumulation of several anticancer nucleosides, ${ }^{11,12}$ and there is some evidence that hENT1 protein abundance correlates with efficacy of nucleoside therapy in leukemic cells ${ }^{25,26}$ and gemcitabinetreated pancreas cancer (JR Mackey et al, submitted). hENT1 is the major means by which cytarabine enters myeloblasts; ${ }^{26}$ low hENT1 activity and RNA expression correlates with poor clinical outcomes in cytarabine-treated acute myelogenous leukemia. ${ }^{29,30}$ Similarly, hENT1 mediates gemcitabine entry in cultured human cells ${ }^{11,12,24}$ and hematopoietic progenitor cells, ${ }^{31}$ and inhibition of hENT1-mediated transport protects cells from cytotoxicity. ${ }^{24}$ Although hENT1 transports fludarabine ${ }^{13}$ and hENT1 expression appears to be linked to drug ex vivo fludarabine sensitivity in chronic lymphocytic leukemia, ${ }^{32}$ the relationship between hENT1 abundance and clinical fludarabine sensitivity is uncertain.

Previously, assays for the quantification of hENT1 protein in clinical samples relied on radiolabeled or fluorescent-labeled NBMPR-binding analyses, which required large numbers of homogeneous viable cells. These studies demonstrated that the abundance of hENT1 protein on human plasma membranes varies greatly, ranging from below 500 NBMPR-binding sites per chronic lymphocytic leukemia cell ${ }^{33}$ to a high of $10^{7}$ sites per BeWo choriocarcinoma cell. ${ }^{34}$ However, NBMPR-based binding analyses cannot be readily performed on lymphomas, due to the technical difficulty of purifying large numbers of malignant cells derived from clinical specimens. In view of the clinical importance of nucleoside analogs in treating NHL patients and the expected correlation between nucleoside transporter abundance and chemosensitivity, we performed a immunohistochemical survey of hENT1 in benign lymphoid tissues and NHL.

In all 15 cases of normal lymphoid tissues we examined in this study, hENT1 was strictly confined to the germinal centers (Figure 1). Interfollicular lymphocytes had no detectable hENT1 immunostaining. This is in keeping with one of our previous studies $^{35}$ in which we reported that lymphocytes in a normal lymph node are negative for hENT1. We did not report the hENT1 reactivity in germinal centers since the normal lymph node case we chose in this previous case did not have prominent germinal centers and the focus of the study was to evaluate the hENT1 reactivity in Hodgkin's lymphoma. ${ }^{35}$ Similar to the previous study, ${ }^{35}$ endothelial cells were positive for hENT1 in all cases.

In contrast to normal lymphoid tissues, hENT1 abundance was markedly heterogeneous among the different histologic subtypes of NHL, as summarized in Table 1. Diffuse large B-cell lymphoma, follicular lymphoma and Burkitt lymphoma/leukemia had immunohistochemical evidence of plasma membrane hENT1. In diffuse large B-cell lymphoma, $45 \%$ of cases were positive for hENT1, while $40 \%$ of cases with follicular lymphoma and $63 \%$ with Burkitt lymphoma/leukemia (thought to derive from early germinal center cells) were positive. A lower frequency of hENT1 positivity was found in mantle cell lymphoma (two of 15, 13\%) and peripheral T-cell lymphomas (three of eight, 37\%). All cases of marginal zone B-cell lymphomas $(n=5)$, small lymphocytic lymphoma/chronic lymphocytic leukemia $(n=10)$, plasmacytoma $(n=3)$, and anaplastic large cell lymphoma $(n=5)$ were negative.

Interestingly, the highest frequency of hENT1 positivity in NHL was identified in lymphomas derived from follicular center cells: CD10-positive diffuse large B-cell lymphoma, follicular lymphoma and Burkitt lymphoma/leukemia. We have previously reported that Reed-Sternberg cells in Hodgkin's lymphoma were positive for hENT1 in roughly $40 \%$ of cases. ${ }^{35}$ There is mounting evidence that Reed-Sternberg cells are derived from follicular centers $^{36-38}$ consistent with the observation that Hodgkin's lymphomas have a frequency of hENT1 positivity comparable to those of CD10-positive diffuse large cell, follicular, and Burkitt lymphomas/leukemias (ie 40-60\%). As described, B-cell neoplasms of other stages of differentiation, including marginal zone B-cell lymphoma, plasmacytoma, acute lymphoblastic lymphoma, chronic lymphocytic leukemia/small lymphocytic lymphoma are all negative for hENT1 or positive in only a small subset of cases (ie mantle cell lymphoma). Thus, expression of hENT1 in lymphoid cells is linked to B-cell differentiation.

The regulation of hENT1 is incompletely understood. In cultured human cancer cells, cellular 
hENT1 protein levels may approximately double between G1 and G2/M phases of the cell cycle, ${ }^{39,40}$ indicating that the cellular content of hENT1 is regulated in a coordinated way with cell cycle. High cellular proliferation rates are associated with high hENT1 abundance, ${ }^{41,42}$ and leukopheresis, ${ }^{43}$ GM-CSF stimulation, ${ }^{41}$ and cytotoxic nucleoside exposure $^{33}$ have been reported to cause 2-6-fold increases in hENT1 in human leukemic cells. In cultured human B-lymphoid cell lines, B-cell activators, such as phorbol 12-myristate 13-acetate and lipopolysaccharide, downregulate hENT1 at the level of mRNA, via a protein kinase C-dependent pathway. Additionally, TNF-alpha downregulates hENT1 activity by a protein kinase C-independent mechanism. ${ }^{44}$ Stimulation of protein kinase $\mathrm{C}$ in cultured human cells (HeLa, MCF-7) causes a rapid increase in hENT1 activity. ${ }^{45}$ Potentially, we may be observing these effects in vivo, where normal germinal centers and lymphomas of follicular origin are driven by these, or other, cytokines.

Although follicular lymphomas derive from germinal center B cells, the absence of hENT1 in $60 \%$ of our cases would be expected to give rise to insensitivity to nucleoside analogs. Gemcitabine has shown only modest activity in patients with refractory follicular lymphoma. ${ }^{8}$ In mantle cell lymphoma, response rates range from 11 to $53 \%$ with single agent fludarabine or cladribine and in a study of 11 patients with mantle cell lymphoma treated with gemcitabine there were only two responses of limited duration. ${ }^{46}$ In our previous report on a patient with refractory mantle cell leukemia, circulating cells were functionally deficient in nucleoside transport activity. ${ }^{35}$ In the current study, cases of follicular lymphoma with foci of transformation show loss of hENT1 expression in the areas of large cells. While the mechanism of the loss of hENT1 in this setting is unknown, the absence of hENT1 expression in the large-cell component may contribute to a relative lack of response to nucleoside analogs in these diseases.

In keeping with studies with chronic lymphocytic leukemia showing low abundance of NBMPR-binding sites, ${ }^{33}$ small lymphocytic lymphomas were uniformly hENT1 negative. The relatively high sensitivity of chronic lymphocytic leukemia/small lymphocytic lymphoma to fludarabine therapy may relate, in part, to the presence of other nucleoside transporters, including hENT2 and hCNT2, that mediate fludarabine entry. ${ }^{32}$

Unfortunately, there are no reliable clinical or laboratory markers to predict as to which patients with NHL may respond to nucleoside therapy. Our observation that follicular derived lymphomas were more frequently hENT1 positive than nonfollicular lymphomas is concordant with clinical experience, where Whelan et $a l^{47}$ observed response to fludarabine in 11 of 23 patients (48\%) with follicular lymphoma, and only two of $11(18 \%)$ with diffuse histology. Similarly, high response rates to fludar- abine were observed for follicular small cleaved cell lymphoma (62\%), follicular mixed small- and largecell lymphoma $(80 \%)$, and follicular large-cell lymphoma (FLCL, 100\%) in another phase II trial, with no responses send in diffuse lymphomas $(n=20) .{ }^{48}$ As hENT1 activity is strongly related to nucleoside drug cytotoxicity in vitro and substantial heterogeneity of staining was determined in this study, the immunohistochemical staining of hENT1 warrants formal prospective evaluation as a predictive tool for guiding the appropriate clinical use of nucleoside analogs in the treatment of follicular cell-derived NHL. The absence of hENT1 may predict those patients unlikely to derive benefit from nucleoside chemotherapy.

\section{Acknowledgements}

We thank Linda Harris (Librarian) and Shelley-Anne Fraser for assistance with manuscript preparation, and Darryl Glubrecht for expert technical assistance. This work was supported by a grant from the Alberta Cancer Foundation.

\section{References}

1 Schiavone EM, De Simone M, Palmieri S, et al. Fludarabine plus cyclophosphamide for the treatment of advanced chronic lymphocytic leukemia. Eur J Haematol 2003;71:23-28.

2 Bernell P, Ohm L. Promising activity of gemcitabine in refractory high-grade non-Hodgkin's lymphoma. Br J Hematol 1998;101:203-204.

3 Santaro A, Devizzi L, Bonfante V, et al. Phase II study with gemcitabine in pretreated patients with Hodgkin's disease (HD) and non-Hodgkin's lymphomas (NHL): results of a multicentre trial (meeting abstract). Proceedings of the Annual Meeting of the American Society of the Clinical Oncologists 1997, Vol. 16, p A71.

4 Garrett TJ, Rule SA, Matczak E, et al. Gemcitabine for relapsed or resistant lymphoma. Proceedings of the Annual Meeting of the American Society of the Clinical Oncologists 1999, Vol. 18, p A100.

5 Savage DG, Rule SA, Tighe M, et al. Gemcitabine for relapsed or resistant lymphoma. Ann Oncol 2000;11: 595-597.

6 Nabhan C, Krett N, Gandhi V, et al. Gemcitabine in hematologic malignancies. Curr Opin Oncol 2001;13: 514-521.

7 Chau I, Harries M, Cunningham D, et al. Gemcitabine, cisplatin and methylprednisolone chemotherapy (GEM-P) is an effective regimen in patients with poor prognostic primary progressive or multiply relapsed Hodgkin's and non-Hodgkin's lymphoma. Br J Haematol 2003;120:970-977.

8 Dumontet C, Morschhauser F, Solal-Celigny P, et al. Gemcitabine as a single agent in the treatment of relapsed or refractory low-grade non-Hodgkin's lymphoma. Br J Haematol 2001;113:772-778.

9 Hagemeister FB. Treatment of relapsed aggressive lymphomas: regimens with and without high-dose therapy and stem cell rescue. Cancer Chemother Pharmacol 2002;49(Suppl 1):S13-S20. 
10 Baldwin SA, Mackey JR, Cass CE, et al. Nucleoside transporters: molecular biology and implications for therapeutics development. Mol Med Today 1999;5: 216-224.

11 Mackey JR, Yao SYM, Smith KM, et al. Gemcitabine transport in Xenopus oocytes expressing recombinant plasma membrane mammalian nucleoside transporters. J Natl Cancer Inst 1999;91:1876-1881.

12 Mackey JR, Baldwin SA, Young JD, et al. The role of nucleoside transport in anticancer drug resistance. Drug Resist Updates 1998;1:310-324.

13 Griffiths M, Yao SYM, Abidi F, et al. Molecular cloning and characterization of a nitrobenzylthioinosineinsensitive (ei) equilibrative nucleoside transporter from human placenta. Biochem J 1997;328:739-743.

14 Griffiths M, Beaumont N, Yao SYM, et al. Cloning of a human nucleoside transporter implicated in the cellular uptake of adenosine and chemotherapeutic drugs. Nat Med 1997;3:89-93.

15 Crawford CR, Patel DH, Naeve C, et al. Cloning of the human equilibrative nitrobenzylmercaptopurine riboside (NBMPR)-insensitive nucleoside transporter ei by functional expression in a transport-deficient cell line. J Biol Chem 1998;273:5288-5293.

16 Ritzel MWL, Yao SYM, Ng AML, et al. Molecular cloning, functional expression and chromosomal localiztion of a cDNA encoding a human $\mathrm{Na}^{+} /$nucleoside cotransporter (hCNT2) selective for purine nucleosides and uridine. Mol Membr Biol 1999;15:203-211.

17 Wang J, Su S-F, Dresser MJ, et al. $\mathrm{Na}^{+}$-dependent purine nucleoside transporter from human kidney: cloning and functional characterization. Am J Physiol 1997;273:F1058-F1065.

18 Ritzel MW, Ng AM, Yao SY, et al. Molecular identification and characterization of novel human and mouse concentrative $\mathrm{Na}^{+}$-nucleoside cotransporter proteins (hCNT3 and mCNT3) broadly selective for purine and pyrimidine nucleosides (system cib). J Biol Chem 2001; 276:2914-2927.

19 Yao SYM, Ng AML, Ritzel MWL, et al. Transport of adenosine by recombinant purine and pyrimidineselective sodium/nucleoside cotransporters from rat jejunum expressed in Xenopus laevis oocytes. Mol Pharmacol 1996;50:1529-1533.

20 Mackey JR, Jennings LL, Clarke ML, et al. Immunohistochemical variation of human equilibrative nucleoside transporter 1 protein in primary breast cancers. Clin Cancer Res 2002;8:110-116.

21 Jaffe ES, Harris LN, Stein H, Vardiman JW, (eds). Pathology and Genetics of Tumours of Hematopoietic and Lymphoid Tissues: World Health Organization Classification of Tumours. IARC Press: Lyon, 2001.

22 Jennings LL, Hao C, Cabrita MA, et al. Distinct regional distribution of human equilibrative nucleoside transporter proteins 1 and 2 (hENT1 and hENT2) in the central nervous system. Neuropharmacology 2001;40:722-731.

23 Dabbagh L, Coupland RW, Cass CE, et al. Immunohistochemical variation of human equilibrative nucleoside transporter 1 protein in primary breast cancers. Clin Cancer Res 2003;9:3213-3214.

24 Mackey JR, Mani RS, Selner M, et al. Functional nucleoside transporters are required for gemcitabine influx and manifestation of toxicity in cancer cell lines. Cancer Res 1998;58:4349-4357.

25 Wiley JS, Jones SP, Sawyer WH. Cytosine arabinoside transport by human leukemic cells. Eur J Cancer Clin Oncol 1983;19:1067-1074.
26 Wiley JS, Jones SP, Sawyer WH, et al. Cytosine arabinoside influx and nucleoside transport sites in acute leukemia. J Clin Invest 1982;69:479-489.

27 Gati WP, Paterson ARP, Belch AR, et al. Es nucleoside transporter content of acute leukemia cells: role in cell sensitivity to cytarabine. Leuk Lymphoma 1998;32:45-54

28 Gati WP, Paterson ARP, Larratt LM, et al. Sensitivity of acute leukemia cells to cytarabine is a correlate of cellular es nucleoside transporter site content measured by flow cytometry with SAENTA-fluorescein. Blood 1997;90:346-353.

29 Petersen AJ, Brown RD, Pope BB, et al. Multiple myeloma: expression of nucleoside transporters on malignant plasma cells and their relationship to cellular proliferation. Leuk Lymphoma 1994;13:491-499.

30 Galmarini CM, Thomas $\mathrm{X}$, Calvo $\mathrm{F}$, et al. In vivo mechanisms of resistance to cytarabine in acute myeloid leukaemia. Br J Haematol 2002;117:860-868.

31 Janowska-Wieczorek A, Cass CE, Graham K, et al. Gemcitabine membrane transport capabilities of normal human hematopoietic progenitor $\left(\mathrm{CD} 34^{+}\right)$cells. Blood 1999;94:279a.

32 Molina-Arcas M, Bellosillo B, Casado FJ, et al. Fludarabine uptake mechanisms in B-cell chronic lymphocytic leukemia. Blood 2003;101:2328-2334.

33 Petersen AJ, Brown RD, Gibson J, et al. Nucleoside transporters, bcl-2 and apoptosis in CLL cells exposed to nucleoside analogues in vitro. Eur J Haematol 1996;56:213-220.

34 Boumah CE, Hogue DL, Cass CE. Expression of high levels of nitrobenzylthioinosine-sensitive nucleoside transport in cultured human choriocarcinoma (BeWo) cells. Biochem J 1992;288:987-996.

35 Reiman T, Clarke ML, Dabbagh L, et al. Differential expression of human equilibrative nucleoside transporter 1 (hENT1) protein in the Reed-Sternberg cells of Hodgkin's disease. Leuk Lymphoma 2202;43: 1435-1440.

36 Marafioti T, Hummel M, Foss HD, et al. Hodgkin and Reed-Sternberg cells represent an expansion of a single clone originating from a germinal center B-cell with functional immunoglobulin gene rearrangements but defective immunoglobulin transcription. Blood 2000;95:1443-1450.

37 Marafioti T, Hummel M, Anagnostopoulos I, et al. Classical Hodgkin's disease and follicular lymphoma originating from the same germinal center B cell. J Clin Oncol 1999;17:3804-3809.

38 Kuppers R, Sousa AB, Baur AS, et al. Common germinal-center B-cell origin of the malignant cells in two composite lymphomas, involving classical Hodgkin's disease and either follicular lymphoma or B-CLL. Mol Med 2001;7:285-292.

39 Pressacco J, Wiley JS, Jamieson GP, et al. Modulation of the equilibrative nucleoside transporter by inhibitors of DNA synthesis. Br J Cancer 1995;72:939-942.

40 Cass CE, Dahlig E, Lau EY, et al. Fluctuations in nucleoside uptake and binding of the inhibitor of nucleoside transport, nitrobenzylthioinosine, during the replication cycle of HeLa cells. Cancer Res 1979;39:1245-1252.

41 Wiley JS, Cebon JS, Jamieson GP, et al. ARP: Assessment of proliferative responses to granulocytemacraphage colony-stimulating factor (GM-CSF) in acute myeloid leukemia using a fluorescent ligand for the nucleoside transporter. Leukemia 1994;8: 181-185. 
42 Smith CL, Pilarski LM, Egerton ML, et al. Nucleoside transport and proliferative rate in human thymocytes and lymphocytes. Blood 1989;74:2038-2042.

43 Powell BL, Gregory BW, Evans JK, et al. Leukapheresis induced changes in cell cycle distribution and nucleoside transporters in patients with untreated acute myeloid leukemia. Leukemia 1991;5:1037-1042.

44 Soler C, Felipe A, Mata JF, et al. Regulation of nucleoside transport by lipopolysaccharide, phorbol esters, and tumor necrosis factor-alpha in human Blymphocytes. J Biol Chem 1998;273:26939-26945.

45 Coe I, Zhang Y, McKenzie T, et al. PKC regulation of the human equilibrative nucleoside transporter, hENT1. FEBS Lett 2002;517:201-205.
46 Dumontet C, Morschauser F, Bouafia F, et al. Phase II study of gemcitabine in patients with refractory or relapsing low grade lymphoproliferative malignancies. Proceedings of the Annual Meeting of the American Society of the Clinical Oncologists 1999, p A415.

47 Whelan JS, Davis CL, Rule S, et al. Fludarabine phosphate for the treatment of low grade lymphoid malignancy. Br J Cancer 1991;64:120-123.

48 Redman JR, Cabanillas F, Velasquez WS, et al. Phase II trial of fludarabine phosphate in lymphoma: an effective new agent in low-grade lymphoma. J Clin Oncol 1992;10:790-794. 